\title{
Scientific approach and practical experience for reconstruction of waste water treatment plants in Russia
}

\author{
Nikolay Makisha ${ }^{1, *}$, and Elena Gogina ${ }^{1}$ \\ ${ }^{1}$ Moscow State University of Civil Engineering (MSUCE), Yaroslavskoye shosse, 26, Moscow, \\ Russia, 129337
}

\begin{abstract}
Protection of water bodies has a strict dependence on reliable operation of engineering systems and facilities for water supply and sewage. The majority of these plants and stations has been constructed in $1970-1980$ 's in accordance with rules and regulations of that time. So now most of them require reconstruction due to serious physical or/and technological wear. The current condition of water supply and sewage systems and facilities frequently means a hidden source of serious danger for normal life support and ecological safety of cities and towns. The article reveals an obtained experience and modern approaches for reconstruction of waste water and sludge treatment plants that proved their efficiency even if applied in limited conditions such as area limits, investments limits. The main directions of reconstruction: overhaul repair and partial modernization of existing facilities on the basis of initial project; - restoration and modernization of existing systems on the basis on the current documents and their current condition; upgrade of waste water treatment plants (WWTPs) performance on the basis of modern technologies and methods; reconstruction of sewage systems and facilities and treatment quality improvement.
\end{abstract}

\section{Introduction}

A long-term study of approaches to wastewater treatment held in MSUCE shows that the most common strategy in the field of construction and reconstruction of WWTPs is the maximum increase of capital and operating costs. The reform of the utilities sector in Russia has not led to its improvement, moreover, after the transfer of responsibility for the majority of treatment facilities to the municipalities, their operation and the condition deteriorated significantly due to the following reasons:

- lack of qualified staff that may carry out operation of the sewage treatment facilities;

- lack of appropriate investments for operation and quality improvement of wastewater treatment facilities;

- lack of manufacturing base for production of equipment for treatment facilities;

- lack of clear program of sewage treatment systems modernization.

\footnotetext{
* Corresponding author: makishana@mgsu.ru
} 


\section{Modern requirements}

According to the state water account, total discharge of wastewater into surface water bodies consists of the following positions:

- Polluted wastewater - 182.4 million cubic meters;

- Without purification - 22.0 million cubic meters;

- Insufficiently purified - 160.4 million cubic meters;

- Standard clean 3.6 million cubic meters;

- Required treatment - 10.5 million cubic meters.

Table 1. Amount of pollutants in wastewater per person worldwide.

\begin{tabular}{|c|c|c|c|c|}
\hline Countries & $\begin{array}{c}\text { BOD } \\
\text { [kg per person } \\
\text { per year] }\end{array}$ & $\begin{array}{c}\text { Suspended solids } \\
\text { [kg per person } \\
\text { per year] }\end{array}$ & $\begin{array}{c}\text { Total nitrogen } \\
\text { [kg per person } \\
\text { per year] }\end{array}$ & $\begin{array}{c}\text { Total phosphorus } \\
\text { [kg per person } \\
\text { per year] }\end{array}$ \\
\hline Denmark & $20-25$ & $30-35$ & $5-7$ & $1.5-2$ \\
\hline Brazil & $20-25$ & $20-25$ & $3-5$ & $0.6-1$ \\
\hline Egypt & $10-15$ & $15-25$ & $3-5$ & $0.4-0.6$ \\
\hline Germany & $18-22$ & $30-35$ & $4-6$ & $1.2-1.6$ \\
\hline India & $10-15$ & - & - & - \\
\hline Italy & $18-22$ & $20-30$ & $3-5$ & $0.6-1$ \\
\hline Sweden & $25-30$ & $30-35$ & $4-6$ & $0.8-1.2$ \\
\hline Turkey & $10-15$ & $15-25$ & $3-5$ & $0.4-0.6$ \\
\hline USA & $30-35$ & $30-35$ & $5-7$ & $1.5-2$ \\
\hline Russia & 14.6 & 23.7 & 2.9 & 1.2 \\
\hline
\end{tabular}

Table 2. Wastewater features in Russia and Europe.

\begin{tabular}{|c|c|c|}
\hline Pollutants & Russia & Europe \\
\hline $\mathrm{BOD}_{5}, \mathrm{mg} / \mathrm{l}$ & $135-176$ & $300-350$ \\
\hline $\mathrm{NH}_{4}, \mathrm{mg} / \mathrm{l}$ & $26-35$ & $30-50$ \\
\hline Total nitrogen, $\mathrm{mg} / \mathrm{l}$ & $30-38$ & $50-80$ \\
\hline $\mathrm{BOD}_{5} / \mathrm{N}$ ratio & $4-5$ & $6-7$ \\
\hline Phosphates, mg/l & $2.3-3.4$ & $7-10$ \\
\hline Total phosphorus, mg/l & $4-9$ & 10 \\
\hline BOD $_{5} / \mathrm{P}$ ratio & $20-34$ & 30 \\
\hline
\end{tabular}

Most of municipal treatment facilities of housing and communal services have a significant degree of technical wear and obsolescence. Thus, if general condition of WWTP is considered only $5 \%$ of the discharged wastewater meet the requirements; $20 \%$ - qualify for the main indicators, but do not remove nutrients to the necessary values; 
75 percent do not meet the requirements for wastewater discharge into water bodies of different values.

There are several reasons why this situation happens. The main factor is the quality of sewage that comes to WWTPs. Table 1 shows data on the number of impurities per person per year in different countries of the world. In Russia, the amount of pollution per capita is several times less than in other countries and this fact determines the quality of waste water, which comes at the sewage treatment plant (table 2) [1-3].

The pollutants ratio needed for normal biological treatment is far from required. This factor has a significant influence on the quality of treated wastewater, as well as the technologies that can and should be applied in the Russian Federation.

We cannot dwell also on the quality requirements of treated wastewater for discharge into the fishery reservoirs (Table 3) [4-6].

Table 3. Requirements for treated waste water in Russia.

\begin{tabular}{|c|c|}
\hline Pollutants & Limited concentration for discharge in water bodies \\
\hline $\mathrm{BOD}_{5}[\mathrm{mg} / \mathrm{l}]$ & 3.0 \\
\hline $\mathrm{N}-\mathrm{NH}_{4}[\mathrm{mg} / \mathrm{l}]$ & 0.39 \\
\hline $\mathrm{N}_{-} \mathrm{NO}_{3}[\mathrm{mg} / \mathrm{l}]$ & 9.1 \\
\hline $\mathrm{N}-\mathrm{NO}_{2}[\mathrm{mg} / \mathrm{l}]$ & 0.02 \\
\hline $\mathrm{P}_{-} \mathrm{PO}_{4}[\mathrm{mg} / \mathrm{l}]$ & 0.2 \\
\hline Suspended solids $[\mathrm{mg} / \mathrm{l}]$ & $5-6$ \\
\hline
\end{tabular}

\section{Current conditions}

A factor of a top importance is efficiency of technological schemes applied on the wastewater treatment plants, which fail to ensure a quality of treatment stated in the regulation documents especially when removal of nitrogen and phosphorus is concerned. Efficiency of ammonia removal may be, in particular, from 20 to $40 \%$, however if up-to-date technologies implemented that value should be at least $80-90 \%$. Similar solutions exist to reduce the concentration of phosphate in treated water [7-9].

Summarizing of above said the following issues could be highlighted:

- Age of WWTP in Russia - the majority of them were launched before year 1990;

- The quantitative ratio of the major contaminants BOD:N:P does not satisfy the required proportion for the biological purification of wastewater;

- Overall reconstruction of WWTP in most cases requires large costs that leads to slow, partial or insufficient reconstruction;

- The use of modern technology with no consideration of local conditions;

- The poor operation of treatment facilities.

The research carried out in MSUCE showed that if operation of well functioning sewage treatment plants is examined the following factors of influence may be pointed out (fig. 1).

The main goals of the WWTP reconstruction to aim at are the following:

- Improvement of the ecological status of water bodies of the Russian Federation

- Achievement the required quality of treatment

- Capacity increase of WWTP;

- Automation of WWTP;

- Reduction of sewage sludge amount. 


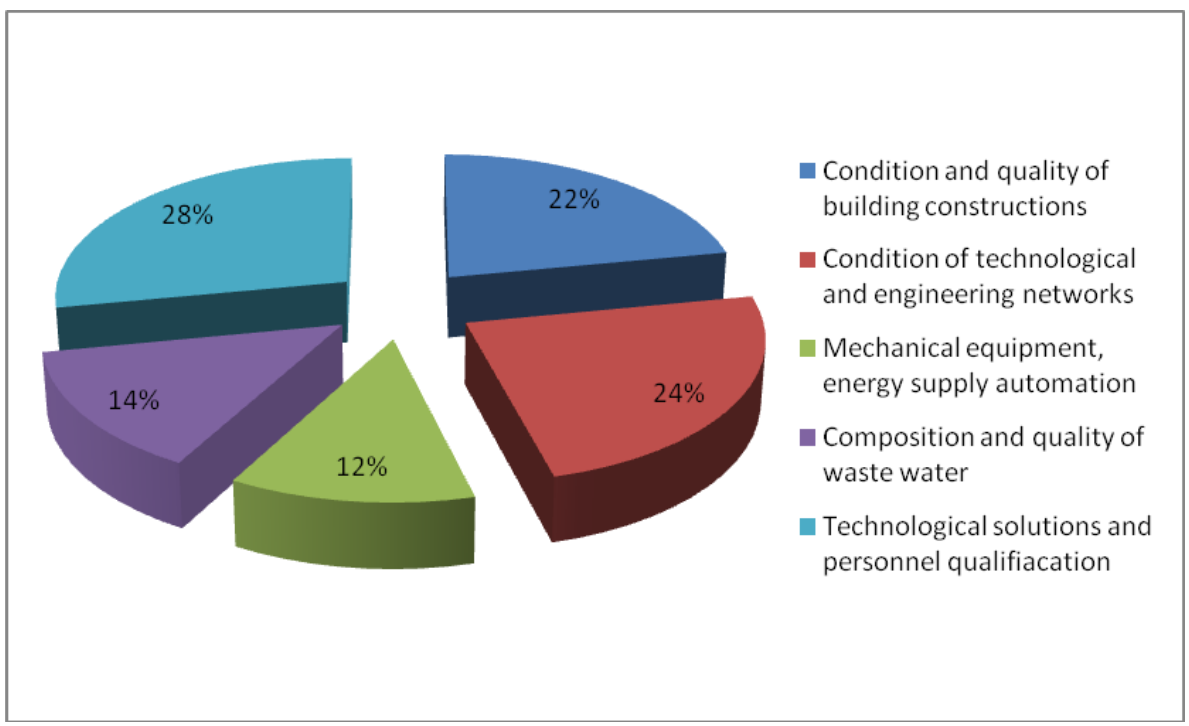

Fig. 1. Factors that influence the waste water treatment plats' operation.

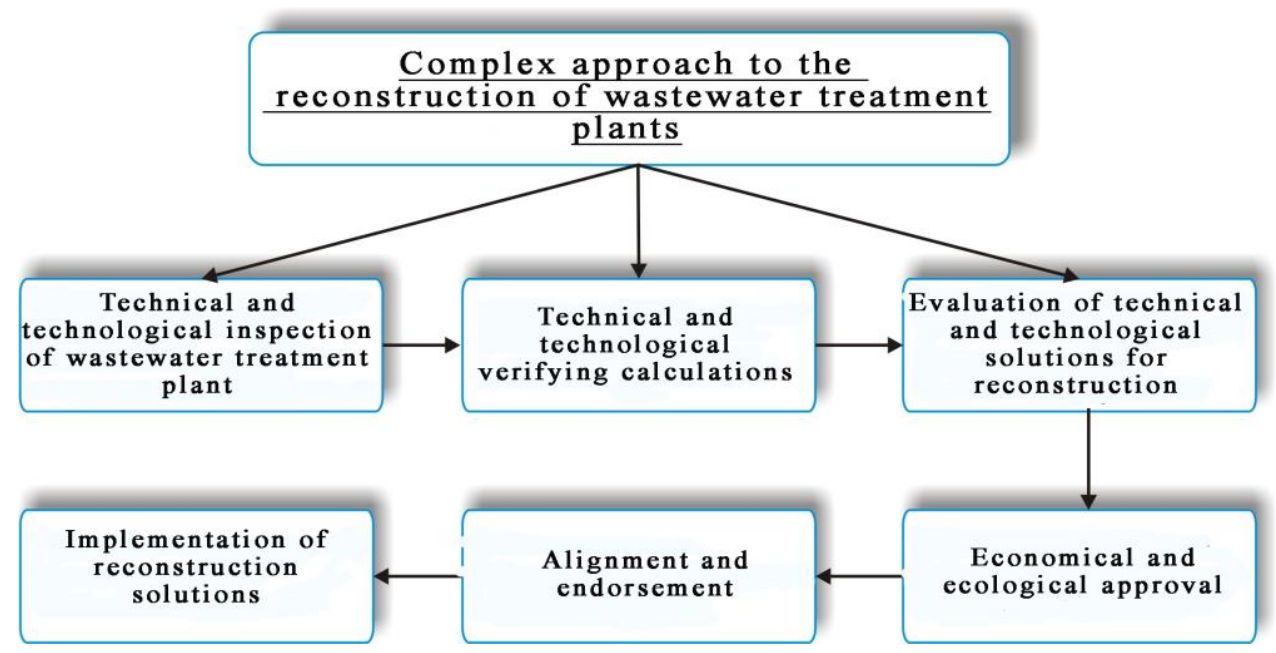

Fig. 2. Stages of reconstruction.

At the same time there is a strong need to focus on the priority reconstruction steps including the following measures [10-14]:

- Flow and concentration control of wastewater delivered to treatment facilities;

- Complex treatment of wastewater providing removal of nutrients;

- Sludge treatment of sewage sludge.

If the goals and measures of modernization are set together solutions to this situation are seen as follows:

- Complex approach - upgrade of the entire treatment facility, not single elements (fig. 2)

- Application of modern technologies considering local (Russia in general or one of its regions in particular) operating conditions of WWTP;

- Design of sewage treatment plants to meet regulatory requirements for wastewater discharges in Russian Federation. 
In each case, before design begins, it is necessary to conduct pre-design comprehensive study of the object to estimate its current state, quality and amount of incoming wastewater. Only afterwards, it normally becomes possible to recommend how to reconstruct the WWTP with maximum use of existing facilities and to implement modern technologies of sewage treatment suitable for the particular object.

Methods of treatment facilities reconstruction of medium and small towns largely differ from the techniques of reconstruction of WWTP for large and mega cities mainly because of irregularity of waste water inlet and wastewater quality. For example, large industrial factories have slighter impact on entire volume of wastewater in the big city than in small one.

\section{Approaches of reconstruction}

First stage of reconstruction of systems and structures of water supply and sanitation has to be aimed at gradual improvement of quality of purified water, without shutting down facilities and their decommissioning.

Within the following reconstruction process, the problem of how to increase the capacity of sewage treatment plants has to be solved first (the quality should comply with so called "full biological treatment of waste water"), quality improvement actions to meet current requirements (BOD, suspended solid, nitrogen and phosphorus compounds etc.) go next [14-16].

It should not be forgotten that existing regulatory document contain almost no instructions on how to run the process of reconstruction and to implement designed solutions for systems and facilities sanitation. Moreover, verifying calculations that based on these documents may not consider current requirements for wastewater treatment.

Numerous researches carried out in MSUCE showed that if a model (typical) projects is applied for several WWTP the sequence and solutions for reconstruction for each of these WWTP may be very different due to specific local conditions. This is the main difference between the design of new treatment facilities and reconstruction of existing structures.

Existing wastewater treatment plants differ from each other by many factors [17-19]:

- Amount of incoming wastewater;

- Quality of wastewater, which depends on type of the industrial enterprises in the city, the capacity and quality of local industrial wastewater treatment plants;

- Degree of physical and moral deterioration of the structures;

- Year of construction and launch;

- Features of WWTP operation;

- Conformity of installations and treatment technology to design decisions;

- Previously conducted reconstruction of individual units or structures.

The complex of works on restoration and reconstruction of the existing sewage treatment plants involves a number of organizational, technological, technical and economic activities, the composition of which depends on the capacity of the treatment facilities and the expected results of the reconstruction. The main activities are [20-22]:

- Examining of the current documents of existing treatment plants and task definition for the reconstruction according to future development of the city.

- Determination of composition and quantity of incoming wastewater;

- Inspection of the facilities, tanks and equipment in order to determine their current state and efficiency of the performance;

- Verifying calculation in order to define current capacity of the plants;

- Evaluation of pre-design solutions for reconstruction on the basis on acquired data and technical task assignment; 
- Project evaluation in accordance to given recommendation;

- Construction and assembly works (with the simultaneous technological supervision);

- Commissioning of equipment and wastewater treatment technology with the development of guidance (rules) for operation of sewage treatment facilities.

\section{Conclusions}

1. Reconstruction of the entire WWTP requires large investments; however there are several ways to reduce costs and to raise overall efficiency of the process.

2. Reconstruction requires reasonable approach in the way to implement the best suitable technology for the specific local conditions.

3. Reconstruction requires a certain procedure to be followed. If this sequence is ignored the aims of the reconstruction may be partially achieved or not achieved in total.

\section{References}

1. A.G. Pervov, A.P. Andrianov, T.P. Gorbunova, A.S. Bagdasaryan, Petr. Chem. 55, 10, 879-886 (2015)

2. I. Gulshin, A. Kuzina, IJAER 10, 21, 42618-42623 (2015)

3. A. Volkov, V. Chulkov, R. Kazaryan, M. Fachratov, O. Kyzina, R. Gazaryan, AMM 580-583, 2281-2284, (2014)

4. A.G. Pervov, A.P. Andrianov, E.B. Yurchevskiy, Petr. Chem. 55, 10, 871-878 (2015)

5. E. Gogina, A. Pelipenko, MATECCONF 73, 03007 (2016)

6. V.N. Varapaev, S.A. Doroshenko, A.Y. Trotsko, A.V. Doroshenko, IJAER 10, 21, 42588-42592 (2015)

7. O. Kuzina, E. Pankratov, V. Tkachev, MATECCONF 86, 05023 (2016)

8. V. Orlov, A. Andrianov, AMM 580-583, 2398-2402 (2014)

9. V.N. Varapaev, A.V. Doroshenko, I.Y. Lantsova, Pr. Eng. 153, 816-823 (2016)

10. N. Zaletova, Y. Voronov, N. Makisha, IJAER 10, 21, 42454-42455 (2015)

11. A.A. Kulakov, Wat. Ecol. 1, 61, 26-40 (2015)

12. N. Makisha, E. Gogina, AMM 361-363, 628-631 (2013)

13. E.S. Gogina, O.A. Ruzhitskaya, O.V. Yantsen. AMR 919-921, 2145-2148 (2014)

14. N. Makisha, E3sconf 6, 01002 (2016)

15. A.G. Pervov, A.P. Andrianov, DWT 35, 1-3, 2-9 (2011)

16. E. Gogina, I. Gulshin, AMM 580-583, 2367-2369 (2014)

17. A. Volkov, O. Kuzina, Pr. Eng. 153, 838-843 (2016)

18. N. Makisha, Pr. Eng. 165, 1087-1091 (2016)

19. A.A. Volkov, A.V. Sedov, P.D. Chelyshkov, D.A. Lysenko, A.V. Doroshenko, IJAER 10, 22, 43269-43272 (2015)

20. N. Makisha, Pr. Eng. 165, 1092-1097 (2016)

21. E. Gogina, I. Gulshin, Pr. Eng. 153, 189-194 (2016)

22. A.G. Pervov, A.P. Andrianov, V.A. Chukhin, R.V. Efremov, IJAER 10, 22, 43517-43525 (2015) 